\title{
TOWARDS A FRAMEWORK FOR SYSTEMIC CREATIVITY IN ENGINEERING ORGANISATIONS
}

\author{
L. Bam ${ }^{1 *} \&$ P.J. Vlok ${ }^{1}$
}

\section{ARTICLE INFO}

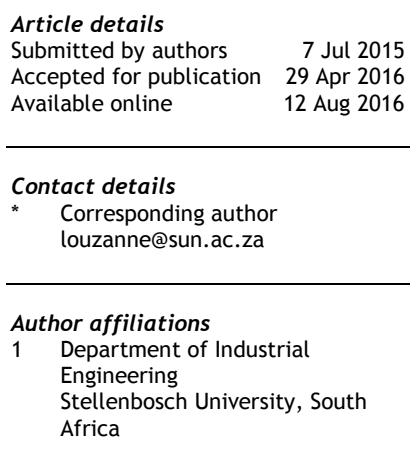

DOI

http://dx.doi.org/10.7166/27-2-1288

\begin{abstract}
This article builds on earlier research that made the case for developing a framework to ensure increased, sustained, creative activity in engineering organisations. A milestone in the development of such a framework is the identification of the elements of creativity that need to be considered. This research reviews the literature on the systems perspective on creativity to identify seven elements of creativity that have been proposed in the literature. A literature review on each of these seven elements is presented to (i) determine whether the element should be included in the framework; (ii) define the element for the purpose of the framework; and (iii) determine whether any author proposes an aspect of creativity that cannot be accommodated under one of the seven elements as they have been defined here.
\end{abstract}

\section{OPSOMMING}

Hierdie artikel volg op vroeër navorsing wat 'n saak gemaak het vir die ontwikkeling van 'n raamwerk om verhoogde, volgehoue, kreatiewe aktiwiteit in ingenieursorganisasies te verseker. 'n Mylpaal in die ontwikkeling van so ' $n$ raamwerk is die identifisering van die elemente van kreatiwiteit wat in ag geneem moet word. Hierdie navorsing hersien die literatuur oor die stelselperspektief op kreatiwiteit om sewe elemente van kreatiwiteit wat in die literatuur voorgestel word te identifiseer. 'n Literatuuroorsig van elkeen van hierdie sewe elemente word aangebied om (i) te bepaal of die element in die raamwerk ingesluit moet word; (ii) die element te definieer vir die doel van die raamwerk; en (iii) vas te stel of enige outeur' $n$ aspek van kreatiwiteit voorstel wat nie onder een van die sewe elemente soos wat hul hier definieer is bygewerk kan word nie.

\section{INTRODUCTION}

This article builds on earlier research [1] that made the case that (i) creativity plays a role throughout the engineering design process, and that it is possible to incorporate creativity into the engineering design process in a systematic manner; (ii) doing this at the very least, holds significant potential for economic benefit; and (iii) due to the complex interplay between creativity and the wide range of factors that influence it, organisational climates and management practices cannot simply be assumed to support creativity effectively. The article proposes that organisations should be managed proactively to support creativity in engineering design.

The earlier work has given rise to the following research question: Can a framework for systemically increasing and measuring creativity in engineering organisations be developed? A sub-research question that originates from this is: What are the key elements that should be taken into account when attempting to develop such a framework for engineering organisations? This sub-research question is the focus of this article.

The article starts with an exploration of the systems perspective on creativity in general, and on organisational creativity in particular, to identify seven elements of creativity defined by various 
authors. At present, there is no literature explicitly linking these seven elements of creativity to engineering organisations. An overview of research findings on each of these seven elements is then presented to provide a more complete understanding of their functioning and of the complexities inherent in each. The findings of this literature review are considered to determine whether the seven elements that have been identified provide a sufficient basis for the development of a framework for systemic creativity in engineering organisations.

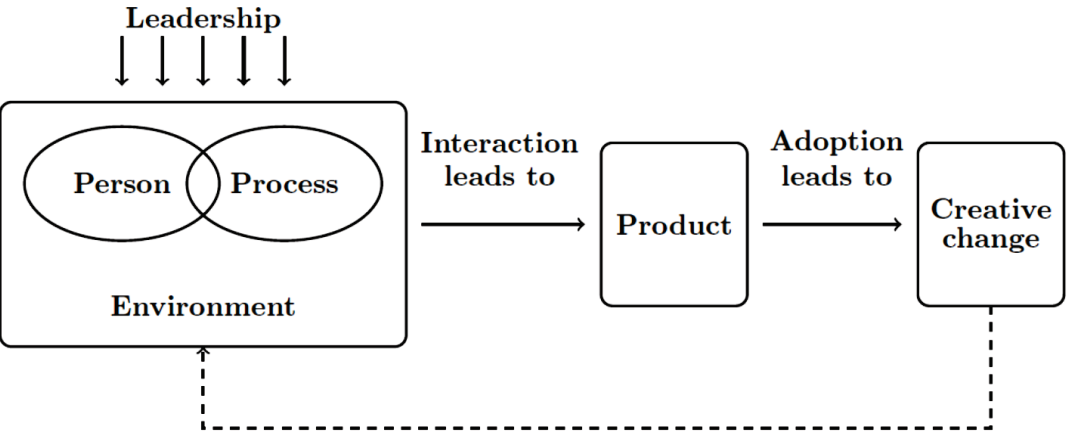

Figure 1: A systems model for understanding organisational creativity (adapted from Puccio \& Cabra [2])

\section{CONTEXTUALISATION: THE SYSTEMS PERSPECTIVE ON CREATIVITY}

Puccio et al. [3] employed a systems perspective on creativity to generate the model to understand organisational creativity, shown in Figure 1. In the model, the person and the process interact within an environment and under the influence of leadership to produce a creative product. When this product is adopted it leads to creative change, which in turn has an influence on the person, the process, the environment, and the leadership. Research supports the appropriateness of a systems approach when considering organisational creativity [2]. According to Sawyer [4], a systems approach to studying creativity "combines individualist perspectives with analyses of the social organisation of creative fields, and the symbolic structure of creative domains." In the model presented in Figure 1, Puccio et al. [3] identified the elements involved in organisational creativity as person, process, environment (also commonly referred to as "place" in the creativity literature), leadership, and product.

A second systems view model of creativity in general (rather than organisational creativity in particular) is presented in Figure 2. In an overview of the systems perspective on creativity, Moran [5] states that this is the most widely-used systems model of creativity. The model was originally developed by Csikszentmihalyi in 1988; an updated version is presented here [6]. The model defines three elements (individual, domain, and field) that interact to produce novelty (the creative product). As shown in Table 1, the 'individual' element can be understood to be equivalent to the 'person' element defined by Puccio et al. [3]. The 'domain' element refers to the cultural or symbolic environment within which the individual attempts to produce the creative product. In this case, it can be viewed as the first component of the 'environment' or 'place' element defined by Puccio et al. [3]. The field is defined by Csikszentmihalyi [6] as "the social organisation of the domain". It can therefore be viewed as the second component of the 'environment' or 'place' element defined by Puccio et al. [3]. Csikszentmihalyi [6] describes the interaction between the individual, the domain, and the field to produce a creative product as follows: "What we call creativity is a phenomenon that is constructed through an interaction between producer and audience". Though it is not explicitly portrayed in the model in Figure 2, Csikszentmihalyi [6] also defines persuasion (which forms part of the interaction between the producer and the audience) as a key element of creativity.

Citing a number of literature reviews, Moran [5] concludes that "the creativity research community has settled on studying creativity based on four components, often referred to as the 'four Ps': person, process, press and product". These four elements of creativity were originally defined by Rhodes [7] as process, product, personality (or person), and place. More recently, Runco [8] proposed the 'six P' framework, including persuasion and potential as elements of creativity. Kozbelt et al. [9] use the "six Ps of creativity" framework to define the aspects of creativity that have been 


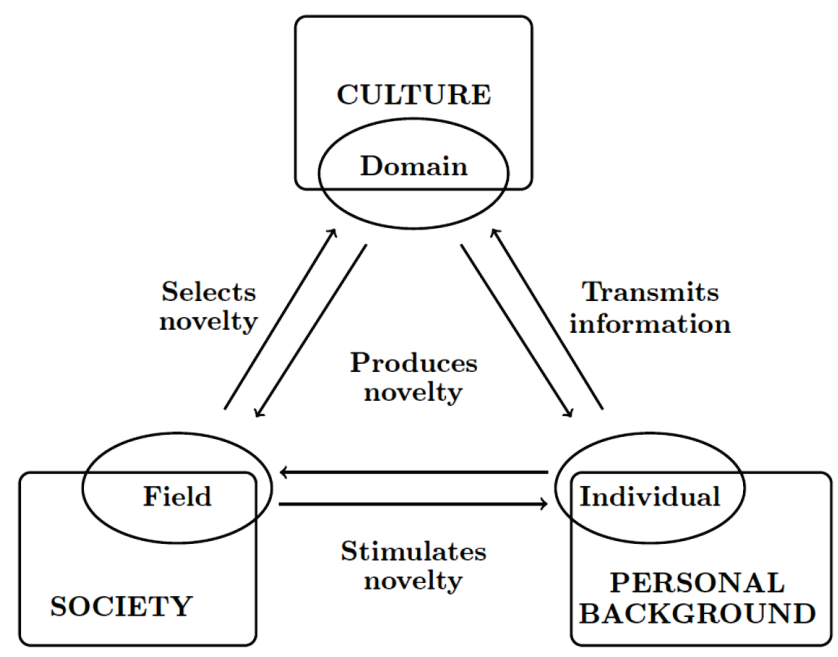

Figure 2: A systems view of creativity (reproduced from Csikszentmihalyi [6])

considered by various theories of creativity since 1926. Table 1 compares the elements of organisational creativity as identified by both Puccio et al. [3] and Csikszentmihalyi [6], with both the four Ps and the six Ps. As shown, the original four Ps correspond directly with four of the five elements identified by Puccio et al. [3], and with three of the four elements identified by Csikszentmihalyi [6]. The 'persuasion' element is identified by both Runco [8] and Csikszentmihalyi [6], while the 'potential' and 'leadership' elements are only proposed by one author each.

In this article, the literature on each of the seven elements will be presented, synthesised, and discussed with the aim of identifying the key factors that need to be taken into account when attempting to develop a framework for increasing systemic creativity in engineering organisations. Though each of the seven elements presented in Table 1 will be explored, emphasis will be placed on the four elements that are common to at least three of the perspectives presented. Except for the leadership element, all other elements will be referred to, using the 'six P' naming convention.

Table 1: Perspectives on the elements of creativity

\begin{tabular}{llll}
\hline $\begin{array}{l}\text { Systems model of } \\
\text { organisational } \\
\text { creativity [3] }\end{array}$ & $\begin{array}{l}\text { Systems model of } \\
\text { creativity [6] }\end{array}$ & Four Ps [5] & Six P framework [8] \\
\hline Person & Individual & Person & Personality \\
$\begin{array}{l}\text { Process } \\
\text { Environment }\end{array}$ & Domain \& Field & Process & Process \\
Product & Press & Place \\
Leadership & Novelty & Product & Product \\
& Persuasion & & Persuasion \\
& & & Potential \\
\hline
\end{tabular}

\section{THE SEVEN ELEMENTS}

\subsection{The 'person' element of organisational creativity}

Puccio and Cabra [2] state that the person element in Figure 1 refers to "individual skills, background, experience, personality, knowledge, motivation and so forth". This description implies that the person element is intended to represent a single individual, or collection of individuals, executing the creative activity.

Engineering projects are often too large in scale or multi-disciplinary in nature for an individual to design the solution in isolation. Teamwork is therefore a characteristic feature of engineering organisations. If one were simply to consider these teams as consisting of a collection of individuals (and by implication, a collection of skills, background, experience, personality, etc.) one would be neglecting to consider the effect of the social dynamics inherent in team work. 
In an overview of the literature on individual and group creativity, Sawyer [4] described the basic question of creativity research as follows: "What is the best scientific explanation of how new things are created?" From this basic question, he derived the applied question: "How can we use these explanations to provide advice to people, groups, and organisations about how to increase their ability to generate new and useful things?" Sawyer [4] proposes that there are three potential solutions to this applied question, each taking a different perspective on group and individual creativity:

1. The individual explanation takes the perspective that creativity is most effectively described in terms of the mental states, behaviours, and personality traits of each of the individuals involved in the creative act;

2. The collective explanation works from the assumption that creative activity is best described in terms of social and cultural contexts and in terms of group dynamics;

3. As one can conclude from the name, the hybrid explanation proposes that one should consider both the properties of the individuals involved and those of the group to explain creativity scientifically.

Sawyer [4] supports the hybrid explanation approach, proposing that "the best scientific explanations of creativity will involve multiple levels of analysis: They will incorporate properties and laws associated with individuals and with groups". An example of a theory of creativity that is based on a hybrid approach is the concept of distributed creativity, which proposes that complex social systems generate the novelty that is associated with creativity [10]. The concept of distributed creativity is based on complexity theory, and it requires a detailed explanation of both psychological and social mechanisms to explain creativity. Finally, Sawyer [4] takes the perspective that each case of creativity is unique, with either the individual-level explanation or the group-level explanation being more significant, depending on the circumstances. Sawyer [4] proceeds to propose a framework - collaborative emergence - that can be used to analyse a specific instance of creativity to determine the relative importance of individual-level and group-level explanations.

From the preceding discussion, it is clear that a framework for incorporating creativity into engineering organisations would need to consider both (i) the individual members of the engineering teams or groups, and (ii) the dynamics of the teams and groups themselves (including their social and cultural context).

\subsubsection{Individuals in an organisational context}

A large portion of early creativity research was dedicated to determining the factors that set creative individuals apart [2]. A few of the prominent findings are summarised here:

- The role of motivation: Sternberg and Kaufman [11] state that "creativity is as much attitudinal as it is cognitive". An individual's motivation towards a task can be classified as (i) no motivation, (ii) intrinsic motivation (i.e., pursuing a task purely for the sake of the satisfaction associated with the task), or (iii) extrinsic motivation (i.e., pursuing a task with a focus on expected rewards that are external to the task). Research has highlighted the importance of intrinsic motivation in encouraging creative activity ([12], [2]). Though the impact of external rewards on an individual's creativity has received significant research attention, Shalley et al. state that "there is little agreement among scholars concerning the likely direction of the effects of such rewards" [13]. More recently, prominent researchers have reviewed earlier research to conclude that, under specific conditions, extrinsic motivation can serve to support intrinsic motivation, thereby positively influencing creative activity [2]. The componential model of creative activity [14] gives motivation as one of the three necessary components that must be present for individual creativity to take place.

- The impact of intelligence: Several studies have concluded that creativity and intelligence have low correlations. Some prominent authors have supported a 'threshold theory' of intelligence, which states that above a threshold IQ value of 120, intelligence has no influence on creativity; however several studies have found little or no evidence to support this theory [15]. It is therefore valid to work from the assumption that creativity and intelligence are two separate constructs. Though intelligence can be safely left out of consideration, the componential model of creativity [14] gives domain-relevant skills as the second of the three necessary components for individual creativity. Domain relevant skills refer to "knowledge, technical skills and special talents" associated with an individual's field of work [2]. 
- The influence of personality: Research shows that personality influences creativity. For example, a person whose personality makes them unwilling to take a risk or defy conventions may never successfully translate their creative potential into creative activity [11]. Research on the influence of personality has identified specific traits that either enable or disable creativity. Feist [16] organised these traits into four groups: cognitive, social, motivationalaffective, and clinical traits. The componential model of creativity [14] gives creativityrelevant skills (such as nonconformity, suspending judgement, perseverance, and selfdiscipline - 'skills' that are closely associated with personality) as the third and final necessary component for individual creativity.

In addition to the role of personal characteristics such as personality and intelligence, social and contextual factors are widely recognised to have an impact on individual creativity. Factors that have been researched to determine their impact on individual creativity include: goal setting ([17], [13]), the expectation of evaluation ([17], [13]), feedback from co-workers [18] or from supervisors [19], perceived organisational support for creativity [18], supervisor close monitoring [19], social relationships [20], and job complexity [21].

In closing, research on the role of bilingualism and multicultural experiences is briefly presented here. This research is particularly relevant when considering creative activity within the South African context.

- The role of bilingualism: Bilingualism is hypothesised to enhance creativity because of how bilingual individuals 'double code' concepts in their memory [22]. Each language in which an individual is proficient therefore provides subtly different perspectives on the same concept. This is hypothesised (i) to facilitate associations and blends of different concepts; and (ii) to enhance mental flexibility [22].

- The influence of multicultural experiences: Leung and Maddux [23] found that exposure to different cultures enhances creative activity. The hypothesis is that this benefit derives from an exposure to (i) knowledge about new or diverse ideas; and (ii) different patterns of thought and action. This allows individuals to overcome their own cultural habits, leaves them open to new experiences, makes them more likely to seek information from unfamiliar sources, and encourages a tendency to synthesise diverse ideas.

\subsubsection{Groups and teams in an organisational context}

Paulus et al. [24] state that "the overwhelming thrust of the literature on groups is that groups are bad for creativity". In fact, in summarising the literature on brainstorming in groups, Paulus et al. [24] state that groups are consistently found to "generate fewer ideas and fewer high-quality ideas compared with individual ideation conditions". In contrast to this, the literature tends to agree that teams can have a "positive impact on productivity and innovation" [24] under the right conditions. Teams are differentiated from groups by factors such as [24]: (i) the length of their existence (teams exist for a longer period of time than groups); (ii) their definition of the roles that are to be fulfilled by each member (in teams, these roles are more formally defined); (iii) the formalisation of the goal that they are working towards (for teams, the goal is more formalised); and (iv) the extent to which they operate as part of a larger organisation (this is more often the case for teams than for groups).

Explanations for the poor creative performance of groups include [24]: (i) the phenomenon of groupthink and other factors that may contribute to inhibit group members from sharing thoughts that go against the dominant train of thought; (ii) social interference or production blocking where the constraints of sharing ideas one at a time leads to lost productivity and the potential loss of creative ideas that cannot be expressed immediately; and (iii) the influence of group members' performance on one another; as group performance generally tends to be low, this may influence individual group members to lower their own performance. Explanations for the innovative potential of teams include [24]: (i) the motivating role of belonging to a team, especially if that team has a significant amount of autonomy; and (ii) the ability to draw on diverse sets of skills and knowledge in developing ideas.

Similar to individual creativity, a variety of social and contextual factors such as diversity, conflict, and the degree to which the environment is perceived to be emotionally supportive are understood to influence team or group creativity [25]. Many researchers have investigated the specific conditions that are conducive to creative productivity in teams. Based on a meta-analysis, Hülsheger et al. [26] conclude that the following team process variables have the most significant impact: (i) 
communication (this links to the impact of social relationships on individual creativity); (ii) vision (this links to the impact of motivation and goal-setting on individual creativity, and to the role of leadership in team creativity); (iii) support for innovation (this links to aspects of the 'place' element of organisational creativity discussed in Section 3.3); (iv) task orientation (this links to the impact of motivation and feedback on individual creativity); and (v) cohesion (this links to the impact of an emotionally-supportive environment). Team input variables such as (i) goal interdependence, (ii) job-relevant diversity, and (iii) team size are also found to play a lesser role [26].

Paulus et al. [24] observe that group creativity research has focused on idea-generation, while team creativity research has focused on innovation (thus, on the implementation of creative ideas). When considering this observation, it is interesting to note the proposal that innovation is "a twocomponent, nonlinear process encompassing both creativity and innovation implementation" [27]. Furthermore, West et al. [27] propose that the innovation process is cyclical, and that there is a greater need for creativity during the early stages of the innovation process.

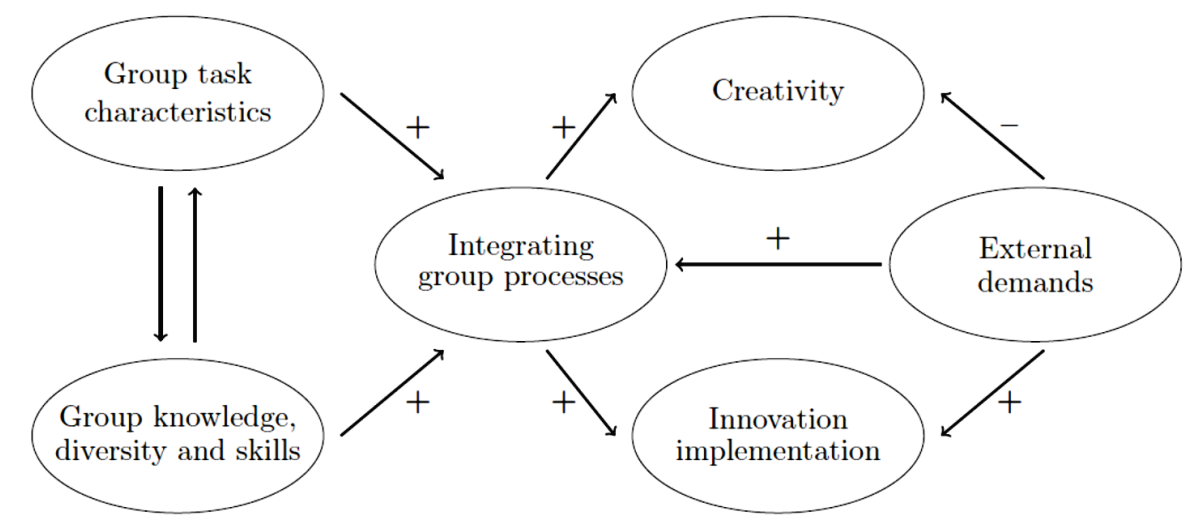

Figure 3: A model of creativity and innovation in work teams (adapted from West et al. [27])

West et al. [27] state that three themes dominate the research on creativity and innovation in work teams. They then propose that a fourth theme, the influence of external demands, should also be added to the themes being investigated. Each of these research themes can be understood to represent an element of work team creativity. Figure 3 depicts the manner in which West et al. [27] propose that each of the key elements influences both creativity and innovation implementation. Each of the four elements is briefly described:

- Group task characteristics: includes the importance and the difficulty of the task or goal;

- Group knowledge, diversity, and skills: refers to the diversity of the characteristics, knowledge, and skills of the team members;

- Integrating group processes: refers to the team processes that facilitate collaboration described earlier in this section; and

- External demands: refers to the context in which the work team operates, and includes the organisational climate and the market environment (the 'place' element of organisational creativity is described more fully in Section 3.3).

While the importance and difficulty of the group task, the diversity of knowledge and skills in the team, and integrating group processes all have a positive influence on both creativity and innovation implementation, West et al. [27] propose that external demands have opposite effects on creativity and innovation respectively, with increased external demands negatively influencing creativity and positively influencing innovation.

Finally, Hargadon and Bechky [28] propose that, at times, "the locus of creative problem solving shifts... from the individual to the interaction of collectives". This perspective takes the teamwork perspective on creativity a step further, moving the focus from "the group and organizational variables that make up the ongoing context for creativity" to "the fleeting coincidence of behaviors that triggers moments when creative insights emerge" [28] to propose that creative insights are, at times, the result of team-level creative synergy that takes place at the collective level. 


\subsection{The 'process' element of organisational creativity}

Puccio and Cabra [2] define the process element in Figure 1 as "the stages of thought people engage in when working alone or with others to creatively address predicaments and opportunities at work".

Divergent thinking is the mental process that is most widely associated with creative thinking [29]. Sternberg and Kaufman [11] define divergent thinking as the "open-ended generation of ideas in response to some kind of task or stimulus". In a work that is still cited in contemporary creativity literature, Sternberg and Davidson [30] define the three most important processes in creative thinking as:

- Selective encoding: the process of discerning between relevant and irrelevant information;

- Selective combination: described by Sternberg and Kaufman [11] as the process of "combining what might originally seem to be isolated pieces of information into a unified whole that may or may not resemble its parts"; and

- Selective comparison: the process of relating newly-acquired information to existing information.

Various researchers have developed methodologies that are intended to provide structured mechanisms for employing creative thinking processes in organisations. Puccio and Cabra [2] define the most prominent methodologies as:

- Creative problem-solving: the method defines a number of steps in the problem-solving process; these steps are designed to mirror an individual's natural problem-solving process [2]. Each step starts with a divergent phase, where a large number of potential solutions are developed, before proceeding to a convergent phase where the most promising solutions are identified and developed in more detail. The methodology also includes one metacognitive step, called 'assessing the situation', to help users determine where to start applying the methodology to their particular problem-solving situation.

- de Bono techniques: de Bono has designed a number of methods to train individuals to think more creatively. Examples include the concept of lateral thinking that "involves deliberate mental efforts to change more automatic or habitual responses that have been shaped through perceptual frameworks" [31], and the 'six thinking hats', described as "direction labels for thinking" [32]. The methods are based on the principle that individuals can be trained to be creative, and the "practical and effective application" [31] of the methods is strongly emphasised.

- $\quad$ Appreciative inquiry: this methodology works from the perspective that it is easier to develop the positive further [2]. The methodology is concerned with developing the organisation and sustaining high performance levels. Similar to the creative problem-solving methodology, appreciative inquiry defines a number of steps that are to be followed, with the first step identifying organisational practices that are working well (hence the positive approach).

- Design thinking: this methodology also comprises a number of steps that are to be followed in the creative process. The emphasis is on thoroughly understanding the user (of the product of creativity) and how the user interacts with the product to identify further opportunities for innovation [2].

- Synectics: this methodology is based on the perspective that creative individuals engage in non-rational, free-thinking thought patterns [2]. Synectics seeks to formalise this way of thinking by encouraging users to engage in a number of different metaphors such as personal analogy (the individual imagines themselves as the problem) or fantasy analogy (the individual imagines the most outrageous, perfect solution and then works towards something more feasible from this starting point).

- TRIZ / theory of inventive problem-solving: The methodology is based on "objective and repeatable engineering principles and practices" [2]. It originated in the 1940s, and was developed by analysing thousands of patents and identifying patterns among these inventions. From the analysis, 40 principles of invention were identified. The "principles are intended to enable individuals to resolve engineering contradictions that are at the essence of the problem" [2]. The 40 principles are incorporated into a methodology that guides users through the process of selecting the most appropriate principle to apply to the problem being considered. 


\subsection{The 'place' element of organisational creativity}

"... there is a road to be travelled from simply talking about creativity or the potential for creativity to real, functionally creative products. What has changed the world is not merely the potential for creativity, but creativity as manifested in functional products. A constraint on creative products however, is that there are many environmental factors that can make it more or less difficult to translate creative ideas into functionally creative products" [11].

Csikszentmihalyi [6] defines the 'field' element in Figure 2 as the social environment, and the 'domain' element as the culture within which creative activity takes place. Puccio and Cabra [2] define the 'place' element in Figure 1 as referring to both the psychological and the physical environment in which an individual or a team works. Though a large number of researchers have attempted to define specific environmental conditions that are conducive to creative activity, Hoff [33] proposes that, of the four Ps of creativity, the 'place' element has received the least research attention. Various measures to evaluate the organisational environment have been developed. Most notable are the KEYS measure developed by Amabile et al. [34] to "evaluate the factors perceived as stimulants or obstacles to creativity in organizational work environments" [35], the Creative Climate Questionnaire developed by Ekvall [36], and the Team Climate Inventory developed by Anderson and West [37].

Hoff [33] distinguishes broadly between the impact of the cultural and psychosocial environment on creativity and the impact of the physical environment on creativity. Puccio and Cabra [2] distinguish between the following aspects of the 'place' element of organisational creativity:

- The organisational culture: refers to the "beliefs and values held by management and communicated to employees through norms, stories, socialization processes, and observations of managerial responses to critical events" [38];

- The organisational structure: refers to the hierarchy within an organisation; it includes lines of authority and responsibility [2];

- The organisational climate: the term is often used interchangeably with organisational culture. However, Tesluk [38] explains that the organisational climate is shaped by both the organisational culture and the organisational structure, and that it communicates "both the organization's goals regarding creativity and the means to achieve those goals" [38] to employees;

- The physical space (within the context of organisational creativity): refers to the physical work environment (typically the office or laboratory space) and the way in which it is configured and decorated;

- The external environment: refers to external forces that exert an influence on the organisation, including financial market conditions, political or social systems, and technological developments [2]; and

- The national culture: this has been shown to have a significant impact on creativity. National cultures have a strong influence on individuals' psychological make-up, which in turn influences their creative activity; specific management styles lead to different results in different cultures; and geopolitical circumstances have also been shown to influence creative activity. Simonton [39] found that societies that are located at the intersection of various cultures have a higher creative output, while research by both Simonton [39] and Therivel [40] shows that a division of political power (i.e., more than one political power or entity) is beneficial to creative activity.

\subsection{The 'product' element of organisational creativity}

"In the world many of us imagine when we first start thinking about creativity and its role in society, the more creative a contribution is, the more it is welcomed. In fact, though, the opposite is often the case. Creative contributions defy the crowd and hence are discouraged, sometimes actively. The more creative a contribution is, the more likely it is to engender resentment and opposition" [11].

Within the context of an organisation, the creative product can take the form of a new process, a new business strategy, a new product that the organisation can market, or any other novel, useful 
contribution to the operation of the organisation. According to Sternberg et al. [41], eight types of creative products can be defined ${ }^{1}$ :

- Replication: a contribution that confirms that the field is in the right place;

- Redefinition: a contribution that attempts to "redefine where the field is" [11];

- Forward incrementation: a contribution that attempts to "move the field forward in the direction it is already going" [11];

- $\quad$ Advance forward incrementation: a forward incrementation that attempts to move the field "beyond where others are ready for it to go"[11];

- Redirection: a contribution that attempts to direct the field "toward a different direction" [11];

- Reconstruction/redirection: a contribution that requires a backward motion before redirecting the field;

- Reinitiation: a contribution that attempts to move the field to a new starting point; and

- Synthesis: a contribution that attempts "to meld together or otherwise synthesise different existing paradigms and merge them into a new one" [11].

The definition of creative product types in relation to an 'existing pattern' is central to the systems view of creativity proposed by Csikszentmihalyi [6], who uses this as motivation for the inclusion of the 'domain' element in the systems view of creativity.

Csikszentmihalyi [6] places a strong focus on the role of society in determining whether a product is in fact creative: "Creativity is not the product of single individuals, but of social systems making judgements about individuals' products". Though the topic has not received a significant amount of attention, a number of researchers have investigated the evaluation of creative products. According to Kwon et al. [42], the three most widely-used measures of product creativity are:

- The consensual assessment technique [43]: This technique involves the creation of a specific type of creative product by a group of participants. The creativity of the products is then evaluated by a group of judges who are deemed to have expertise in the type of product. The judges are given minimal guidance on how they should judge the creativity of the product, and they are also not asked to explain or defend their evaluation method [44]. Therefore, the consensual assessment technique suggests that the best assessment of creativity is the combined, subjective opinion of a number of experts in a particular field. The validity of the consensual assessment technique has been confirmed by large a number of studies [45].

- The creative product semantic scale ([46], [47]; [48], [49]): This is an assessment instrument that uses a structured questionnaire to analyse a product's creativity. Three main factors: (i) novelty (including consideration of new materials, new processes, new concepts, etc.), (ii) resolution (i.e., how well the product serves its intended purpose), and (iii) elaboration and synthesis, also known as style (i.e., how well/elegantly the product concept is realised), are assessed. Each of the three main factors is divided into a further nine categories, and a total of 55 adjective pairs (for which a user selects a rating on a 7-point scale) are used in the assessment.

- The product creativity model [50]: The tool is designed to measure product creativity from the consumer's perspective. Three aspects of product creativity are analysed: (i) attribute (defined as the perception of product creativity, and based on the creative product semantic scale (CPSS) assessment described previously); (ii) affect (defined as the emotional impact of product creativity, measured in terms of the pleasure and arousal that it generates in the judge - i.e., the consumer); and (iii) preference (this evaluates the consumer's interest in creativity as well as the importance of creativity to the consumer). Like the CPSS, 41 adjective pairs are answered using a 7-point Likert scale.

As a closing thought on the evaluation of creative products, recent research has highlighted the influence of cultural perspectives on defining and valuing creative products [51]. Lan and Kaufman [51] found that, while the explicit beliefs about creativity of the American and Chinese cultures share many similarities, there is some divergence when it comes to their implicit beliefs about creativity. As an example, while Americans attach a large amount of value to novelty (a ground-

1 The definitions given here use the term 'field'; the term is also used in Figure 2. However, the term 'field' as used by Sternberg and Kaufman [11] is equivalent to the term 'domain' used by Csikszentmihalyi [6] in Figure 2, not to the term 'field' as used in this figure. 
breaking concept, for example), the Chinese tend to show a greater appreciation for creativity within constraints (for an existing concept that has been re-imagined, for example) [51].

\subsection{The influence of leadership on organisational creativity}

“... leadership behaviour has emerged as the [sic] one of the most potent variables in predicting creativity in teams and organisation" [2].

There is a wealth of literature on the impact of leadership on organisational creativity. One perspective is that leadership has a strong influence on the work environment, and therefore on the 'place' element of organisational creativity [2]. Recent research by Hill et al. [52] supports this perspective by proposing that the central task that a leader must fulfil, if an organisation is to be innovative, is not to create or to sell a vision, but rather to create an organisational context that supports innovation.

A second perspective, suggested by Puccio et al. [3], is that the link between leadership and creativity is change [2]. As illustrated in Figure 1, organisational creativity culminates in change whether it be social change, personal change, innovation, or whatever. According to Puccio et al. [3], leaders often need to act as the catalyst for change in an organisational context [2].

A third perspective is that leadership has a significant influence on the 'person' element of organisational creativity. In relation to leadership style, many researchers have found that transformational leadership in particular has a positive impact on organisational creativity ([53], [54], [55], [56]). Transformational leadership has four key characteristics [57]: charisma (providing vision and mission); inspiration (communicating high expectations); intellectual stimulation (promoting intelligence and careful problem solving); and individualised consideration (treating each employee individually). Transformational leadership is understood to influence individuals' creativity through psychological empowerment [58]. This is enacted through a wide variety of mechanisms, including: encouraging individuals to take risks, thereby encouraging divergent thinking [56]; assuring individuals that their ideas are valued, thereby encouraging them to voice creative ideas [56]; and increasing motivation [59]. Shin et al. [59] argue that "among the team contextual factors, leadership plays the dominant role in workplaces". From the aforementioned, it is evident that leadership is understood to have an impact on the holistic understanding of the 'person' element (as it has been defined in this article), incorporating both the individual and the team or group in the organisational context.

Some interesting findings on the relationship between transformational leadership and creativity include the following:

- Gumusluoglu and Ilsev [58] found that there is a relationship between transformational leadership and an organisation's level of innovation;

- Wang and Rode [60] found that the relationship between transformational leadership and employee creativity was only significant when the employee identified with the leader, and when there was an innovative work climate;

- Shin et al. [59] found that "cognitive team diversity was positively related to individual creativity only when transformational leadership was high"; and

- Of particular interest to engineering organisations where work is performed by multidisciplinary teams, Shin and Zhou [54] found that there is an interaction between the educational diversity of team members and transformational leadership, with team creativity increasing when both variables are present.

\subsection{The persuasion element of organisational creativity}

The persuasion element of creativity was defined by Simonton [61]. It refers to the phenomenon of creative individuals changing the way that those around them think, thus influencing the creative product that is produced [9].

In his systems view model of creativity, Csikszentmihalyi [6] offers a different perspective on persuasion. His model emphasises the role of society (or the 'audience') in determining whether a product is perceived as creative. He argues [6] that, by implication, persuasion to convince the audience that a product is creative plays a central role in the existence of creativity. 


\subsection{The 'potential' element of organisational creativity}

The 'potential' element of creativity was defined by Runco [62] specifically in an educational context. Here, it is argued, a clear distinction should be made between "unambiguous creative performance" and creative potential [62]. Subsequently, Runco [63] suggested that adding 'potential' to the six P model allows the model to be re-organised, with one branch of it focusing on creative performance and the other on creative potential. The creative performance branch incorporates the 'product' and 'persuasion' elements of creativity, as well as any other unambiguous manifestations of creativity. In contrast, the creative potential branch incorporates the 'person' and 'place' elements, as well as any other perspective that "appreciates yet unfulfilled possibilities and subjective processes" [9]. The creative potential branch can also be understood to incorporate the 'process' element.

\section{SYNTHESIS}

The 'person' element of creativity should be understood to refer to both the individuals involved in the creative activity and the group or team involved. Both the systems view model, developed by Csikszentmihalyi [6], and the six P framework define 'persuasion' as a distinct element of creativity. However, it could be argued that, in a framework that takes an organisational perspective, and where the 'person' element is defined as encompassing both the individual involved in the creative activity and the social dynamics of the group or team involved, 'persuasion' can be viewed as part of the 'person' element. An individual's ability to persuade can be linked to that individual's personality, and even their domain-relevant skills, while the influence of the persuasive ability on the rest of the group or team is considered as part of the social dynamics involved in group or team work.

The literature points to strong links between the 'leadership', 'place', and 'person' elements of creativity. It has been proposed that the significant impact of leadership on creativity can (at least in part) be ascribed to the large influence that leadership has on both the 'place' and the 'person' elements.

The 'potential' element of creativity was developed for use specifically in an educational environment. It is primarily concerned with validating creative potential (as opposed to actualised creative productivity). The primary objective of a framework for systemic creativity in engineering organisations would be to translate the creative potential that is present in an organisation to actual creative productivity in a sustainable manner. The literature proposes that the 'potential' element of creativity can be understood to incorporate the 'person', 'place', and 'process' elements of creativity.

\section{CONCLUSION}

From a synthesis of two systems-view models of creativity and the four $\mathrm{P}$ and the six $\mathrm{P}$ definitions of the aspects of creativity, seven elements of creativity that have been defined by various authors were identified: the person, process, place, product, the influence of leadership, persuasion, and potential. The literature on each of these elements was presented in an attempt to provide a more complete understanding of their functioning and of the complexities inherent in each. This literature overview has also served to define the scope of each of the elements in order to develop a framework for systemic creativity in engineering organisations.

The seven elements that were investigated were identified based on an investigation of several sources in the review literature. The literature presented on each of the elements was the result of a thorough investigation of the literature on creativity. Though there are undoubtedly multiple alternative suggestions for the elements of creativity in the literature, none of the literature that was investigated throughout the course of this research described any facet of creativity that could not be accommodated under the seven elements of creativity as they have been defined here. It is therefore proposed that the seven elements that have been defined in this study form a sufficient basis for the development of a framework for systemic creativity in engineering organisations.

Furthermore, as argued in Section 4, it is proposed that the 'persuasion' element could also be included under the 'person' element in the way that it has been defined here; and that the 
'potential' element could either be viewed as a distinct component, or it could be understood as part of the 'person', 'place', and 'process' elements.

This study has answered the sub-research question: What are the key elements that should be taken into account when attempting to develop a framework for systemic creativity in engineering organisations? In doing so, it has mapped the solution space for a framework for systemic creativity in engineering organisations, and so has made progress towards answering the main research question: Can a framework for systemically increasing and measuring creativity in engineering organisations be developed?

\section{REFERENCES}

[1] Oosthuizen, L. and Vlok, P.J. 2015. The absence of a creative focus in the conventional engineering design process: Identifying research opportunities to address this, South African Journal of Industrial Engineering, vol. 27, no. 1, pp. 137-150.

[2] Puccio, G.J. and Cabra, J.F. 2010. Organizational creativity: A systems approach, in The Cambridge handbook of creativity (J.C. Kaufman and R.J. Sternberg, eds), Cambridge: Cambridge University Press, ch. 8, pp. 145-173.

[3] Puccio, G., Murdock, M. and Mance, M. 2007. Creative leadership: Skills that drive change, Thousand Oaks, California: Sage.

[4] Sawyer, R.K. 2010. Individual and group creativity, in The Cambridge handbook of creativity (J.C. Kaufman and R.J. Sternberg, eds), Cambridge: Cambridge University Press, ch. 19, pp. 366-380.

[5] Moran, S. 2009. Creativity: A systems perspective, in The Routledge companion to creativity (T. Rickards, M.A. Runco, and S. Moger, eds), New York: Routledge, ch. 24, pp. 292-301.

[6] Csikszentmihalyi, M. 1999. The impliations of a systems perspective for the study of creativity, in Handbook of creativity (R.J. Sternberg, ed.), Cambridge: Cambridge University Press, ch. 16, pp. 313-338.

[7] Rhodes, M. 1961. An analysis of creativity, Phi Delta Kappan, vol. 42, no. 7, pp. 305-310.

[8] Runco, M.A. 2007. Creativity: Theories and themes: Research, development, and practice, New York: Academic Press.

[9] Kozbelt, A., Beghetto, R.A. and Runco, M.A. 2010. Theories of creativity, in The Cambridge handbook of creativity (J.C. Kaufman and R.J. Sternberg, eds), Cambridge: Cambridge University Press, ch. 2, pp. 2047.

[10] Sawyer, R.K. and DeZutter, S. 2009. Distributed creativity: How collective creations emerge from collaboration, Psychology of Aesthetics, Creativity, and the Arts, vol. 3, no. 2, pp. 81-92.

[11] Sternberg, R.J. and Kaufman, J.C. 2010. Constraints on creativity: Obvious and not so obvious, in The Cambridge handbook of creativity (J.C. Kaufman and R.J. Sternberg, eds), Cambridge: Cambridge University Press, ch. 24, pp. 467-482.

[12] Hennesey, B.A. 2010. The creativity-motivation connection, in The Cambridge handbook of creativity (J.C. Kaufman and R.J. Sternberg, eds), Cambridge: Cambridge University Press, ch. 18, pp. $342-365$.

[13] Shalley, C.E., Zhou, J. and Oldham, G.R. 2004. The effects of personal and contextual characteristics on creativity: Where should we go from here?, Journal of Management, vol. 30, no. 6, pp. 933-958.

[14] Amabile, T.M. 1996. Creativity in context: Update to the social psychology of creativity, Boulder, CO: Westview.

[15] Kim, K.H., Cramond, B. and Vantassel-Baska, J. 2010. The relationship between creativity and intelligence, in The Cambridge handbook of creativity (J.C. Kaufman and R.J. Sternberg, eds), Cambridge: Cambridge University Press, ch. 21, pp. 395-412.

[16] Feist, G.J. 2010. The function of personality in creativity: The nature and nurture of the creative personality, in The Cambridge handbook of creativity (J.C. Kaufman and R.J. Sternberg, eds), Cambridge: Cambridge University Press, ch. 6, pp. 113-130.

[17] Shalley, C.E. 1995. Effects of coaction, expected evaluation, and goal setting on creativity and productivity, Academy of Management Journal, vol. 38, no. 2, pp. 483-503.

[18] Zhou, J. and George, J.M. 2001. When job dissatisfaction leads to creativity: Encouraging the expression of voice, Academy of Management Journal, vol. 44, no. 4, pp.682-696.

[19] Zhou, J. 2003. When the presence of creative coworkers is related to creativity: Role of supervisor close monitoring, developmental feedback, and creative personality, Journal of Applied Psychology, vol. 88, no. 3, pp. 413-422.

[20] Perry-Smith, J.E. 2006. Social yet creative: The role of social relationships in facilitating individual creativity, Academy of Management Journal, vol. 49, no. 1, pp. 85-101.

[21] Oldham, G.R. and Cummings, A. 1996. Employee creativity: Personal and contextual factors at work, Academy of Management Journal, vol. 39, no. 3, pp. 607-634.

[22] Lubart, T.I. 2010. Cross-cultural perspectives on creativity, in The Cambridge handbook of creativity (J.C. Kaufman and R.J. Sternberg, eds), Cambridge: Cambridge University Press, ch. 14, pp. 265-278.

[23] Leung, A.K., Maddux, W.W., Galinsky, A.D. and Chiu, C. 2008. Multicultural experience enhances creativity, American Psychologist, vol. 63, no. 3, pp. 169-181.

[24] Paulus, P.B., Nakui, T. and Putman, V.L. 2006. Group brainstorming and teamwork: Some rules for the road to innovation, in Creativity and innovation in organizational teams (L. Thompson and H.-S. Choi, eds), Mahwah: Lawrence Erlbaum Associates, ch. 4, pp. 69-86. 
[25] Paulus, P.B. and Dzindolet, M. 2008. Social influence, creativity, and innovation, Social Influence, vol. 3, pp. 228-247.

[26] Hülsheger, U.R., Anderson, N. and Salgado, J.F. 2009. Team-level predictors of innovation at work: A comprehensive meta-analysis spanning three decades of research, Journal of Applied Psychology, vol. 94, no. 5, pp. 1128-1145.

[27] West, M.A., Sacramento, C.A. and Fay, D. 2006. Creativity and innovation implementation in work groups: The paradoxical role of demands, in Creativity and innovation in organizational teams (L. Thompson and H.-S. Choi, eds), Mahwah: Lawrence Erlbaum Associates, ch. 7, pp. 137-160.

[28] Hargadon, A.B. and Bechky, B.A. 2006. When collections of creatives become creative collectives: A field study of problem solving at work, Organization Science, vol. 17, no. 4, pp. 484-500.

[29] Runco, M.A. 2010. Divergent thinking, creativity and ideation, in The Cambridge handbook of creativity (J.C. Kaufman and R.J. Sternberg, eds), Cambridge: Cambridge University Press, ch. 22, pp. 413-446.

[30] Sternberg, R.J. and Davidson, J.E. 1983. Insight in the gifted, Educational Psychologist, vol. 18, pp. 5157.

[31] Dingli, S. 2009. Thinking outside the box: Edward de Bono's lateral thinking, in The Routledge companion to creativity (T. Rickards, M.A. Runco and S. Moger, eds), New York: Routledge, ch. 28, pp. 338-350.

[32] de Bono, E. 1999. Six thinking hats, Boston: Little, Brown and Company.

[33] Hoff, E. 2014. The creative place: The impact of different environmental factors on creativity, in Creativity research: An interdisciplinary and multidisciplinary research handbook, (Shiu, E., ed.), New York: Routledge, ch. 6, pp. 103-126.

[34] Amabile, T.M., Burnside, R.M. and Gryskiewicz, S.S. 1999. User's manual for assessing the climate for creativity: A survey from the center for creative leadership, Greensboro: Center for Creative Leadership.

[35] Cirella, S., Radaelli, G. and Shani, A.B. 2014. Team creativity: A complex adaptive perspective, Management Research Review, vol. 37, no. 7, pp. 590-614.

[36] Ekvall, G. 1996. Organizational climate for creativity and innovation, European Journal of Work and Organizational Psychology, vol. 5, pp. 105-123.

[37] Anderson, N.R. and West, M.A. 1998. Measuring climate for work group innovation: Development and validation of the team climate inventory, Journal of Organizational Behavior, vol. 19, pp. 235-258.

[38] Tesluk, P.E., Farr, J.L. and Klein, S.R. 1997. Influences of organizational culture and climate on individual creativity, Journal of Creative Behavior, vol. 31, no.1, pp. 27-41.

[39] Simonton, D.K. 1984. Genius, creativity and leadership, Cambridge: Harvard University Press.

[40] Therivel, W.A. 1995. Long-term effect of power on creativity, Creativity Research Journal, vol. 8, no. 2, pp. 173-192.

[41] Sternberg, R.J., Kaufman, J.C. and Pretz, J.E. 2002. The creativity conundrum: A propulsion model of kinds of creative contributions, New York: Psychology Press.

[42] Kwon, J., Lee, M. and Kim, H.-R. 2014. Does a creative designer necessarily translate into the creative design of a product? Exploring factors facilitating the creativity of a new product, Creativity and Innovation Management. doi:10.111/caim.12103.

[43] Amabile, T.M. 1983. The social psychology of creativity, New York: Springer.

[44] Kaufman, J.C., Lee, J., Baer, J. and Lee, S. 2007. Captions, consistency, creativity, and the consensual assessment technique: New evidence of reliability, Thinking Skills and Creativity, vol. 2, no. 2, pp. 96 106.

[45] Hennesey, B.A. 1994. The consensual assessment technique: An examination of the relationship between ratings of product and process creativity, Creativity Research Journal, vol. 7, no. 2, pp. 193-208.

[46] Besemer, S.P. 1998. Creative product analysis matrix: Testing the model structure and a comparison among products - Three novel chairs, Creativity Research Journal, vol. 11, pp. 333-346.

[47] Besemer, S.P. and O'Quin, K. 1999. Confirming the three-factor creative product analysis matrix model in an American sample, Creativity Research Journal, vol. 12, no. 4, pp. 287-296.

[48] Besemer, S.P. 2000. Creative product analysis to foster innovation, Design Management Journal, vol. 11, no. 4, pp. 59-64.

[49] O'Quin, K. and Besemer, S.P. 2006. Using the creative product semantic scale as a metric for resultsoriented business, Creativity and Innovation Management, vol. 15, no. 1, pp. 34-44.

[50] Horn, D. and Salvendy, G. 2006. Product creativity: Conceptual model, measurement and characteristics, Theoretical Issues in Ergonomics Science, vol. 7, no. 4, pp. 395-412.

[51] Lan, L. and Kaufman, J.C. 2012. American and Chinese similarities and differences in defining and valuing creative products, Journal of Creative Behavior, vol. 46, no. 4, pp. 285-306.

[52] Hill, L.A., Brandeau, G., Truelove, E. and Lineback, K. 2014. Collective genius, Harvard Business Review, vol. 92 , no. 6 , pp. $94-102$.

[53] Shin, S.J. and Zhou, J. 2003. Transformational leadership, conservation, and creativity: Evidence from Korea, The Academy of Management Journal, vol. 46, no. 6, pp. 703-714.

[54] Shin, S.J. and Zhou, J. 2007. When is educational specialization heterogeneity related to creativity in research and development teams? Transformational leadership as a moderator, The Journal of Applied Psychology, vol. 92, no. 6, pp. 1709-1721.

[55] Gong, Y., Huang, J. and Farh, J. 2009. Employee learning orientation, transformational leadership, and employee creativity: The mediating role of employee creative self-efficacy, Academy of Management Journal, vol. 52, no. 4, pp. 765-778.

[56] Shin, Y. and Eom, C. 2014. Team proactivity as a linking mechanism between team creative efficacy, transformational leadership, and risk-taking norms and team creative performance, The Journal of Creative Behavior, vol. 48, no. 2, pp. 89-114. 
[57] Bass, B.M. 1990. From transactional to transformational leadership: Learning to share the vision, Organizational Dynamics, vol. 18, no. 3, pp. 19-31.

[58] Gumusluoglu, L. and Ilsev, A. 2009. Transformational leadership, creativity, and organizational innovation, Journal of Business Research, vol. 62, no. 4, pp. 461-473.

[59] Shin, S.J., Kim, T., Lee, J. and Bian, L. 2012. Cognitive team diversity and individual team member creativity: A cross-level interaction, Academy of Management Journal, vol. 55, no. 1, pp. 197-212.

[60] Wang, P. and Rode, J.C. 2010. Transformational leadership and follower creativity: The moderating effects of identification with leader and organizational climate, Human Relations, vol. 63, no. 8, pp. 11051128.

[61] Simonton, D.K. 1990. History, chemistry, psychology, and genius: An intellectual autobiography of historiometry, in Theories of creativity (M.A. Runco and R.S. Albert, eds), Newbury Park, CA: Sage, pp. 92-115.

[62] Runco, M.A. 2003. Education for creative potential, Scandinavian Journal of Educational Research, vol. 47, no. 3, pp. 317-324.

[63] Runco, M.A. 2008. Creativity and education, New Horizons in Education, vol. 56, no. 1, pp. 107-115. 